\title{
Interactive app-based services: Recovery evaluations and the mediating role of satisfaction in the relationship between customer-brand engagement and electronic word of mouth
}

\section{Radhakrishna Bhimavarapu}

IBS Hyderabad, a Constituent of IFHE, Deemed to be University, India

\section{Pankaj Kumar Mohanty}

IBS Hyderabad, a Constituent of IFHE, Deemed to be University, India

\section{Anitha Acharya}

IBS Hyderabad, a Constituent of IFHE, Deemed to be University, India

\section{Manish Gupta}

School of Management, Mahindra University, India

manish.gupta.research@gmail.com

\section{Abstract}

Based on the theory of co-creation and resource-based theory, this study examines the differential impact of varying levels of customer participation in service recovery (firm, customer, and joint) on recovery satisfaction, customer-brand engagement (CBE), and electronic-word of mouth (e-WoM). Besides, using social exchange theory, this study examines the mediating role of consumers' recovery satisfaction in the relationship between the types of service recovery and electronic word of mouth (e-WoM). The data to accomplish the research objectives was collected from 495 customers of interactive food delivery apps in India. The experimental design was used to collect the data. The multivariate analysis of variance (MANOVA) and PROCESS macro techniques were used to test the hypotheses. The findings suggest that joint recovery results in better recovery evaluations such as $\mathrm{CBE}$, recovery satisfaction, and e-WoM. Also, recovery satisfaction mediated the relationship between CBE and e-WoM. These findings provide empirical evidence for the linkages among the theory of co-creation, resource-based theory, and social exchange theory. The marketers of interactive food delivery apps may use these findings to ascertain which recovery type they should emphasize to improve recovery satisfaction. Moreover, they are encouraged to take steps for improving recovery satisfaction as CBE affects e-WoM through recovery satisfaction.

Keywords: service recovery, satisfaction, customer-brand engagement, e-word of mouth, interactive food delivery apps.

\section{Introduction}

Technology-based interactive apps, especially mobile apps, are widely used for service delivery by individuals, businesses, and communities (Verkijika \& Wet, 2019). According to a market research study, mobile app downloads across the globe are expected to cross 258 billion by 2022 (Statista, 2019). However, the competition is intense (Lim et al., 2015) in the app market and service failure is one of the major reasons that may lead to customer defection thereby hampering an app's market share (Hsu et al., 2019). The customer retention rate, according to Statista 2019 study, decreases significantly over time in the case of mobile apps. Thus, it is 
important for the app-based service firms to know the ways and means through which they can improve the customer retention rate. In the academic literature, the topic 'service recovery in the app-based services' has received little attention despite its growing importance (Hsu et al., 2019). A few of the past studies suggest that customers' involvement in the service recovery process yields better results and improves customer satisfaction (Cheung \& To, 2016).

Although limited in number, prior studies on app-related service failures have examined the antecedents of the technology failure (Dabholkar \& Spaid, 2012); interactivity (Zhu et al., 2013); technology anxiety (Hsu et al., 2019). There are few studies examining customer participation in the recovery process and its outcomes in the mobile app services. Co-creation of recovery helps a firm to improve customer recovery perceptions if the customers are a part of cocreation during the service delivery (Heidenreich et al., 2015). Scholars have argued that customer participation in the service recovery process facilitates interaction between the customer resources such as time and effort with the firm resources such as employees and technology during the co-created recovery with the help of resource integration ( $\mathrm{Xu}$ et al., 2014). Further, prior studies have examined the impact of co-created recovery on recovery outcomes such as recovery satisfaction and future intention to co-create (Dong et al., 2016; Suganathan et al., 2017; Bagherzadeh et al., 2020). It may be that there is greater scope for interaction through resource integration in the recovery process (Xu et al., 2014).

Customer involvement in service recovery may enhance customer's emotional bonding with the service provider resulting in engagement with the brand (Van Vaerenbergh et al., 2018). The term customer-brand engagement is defined as "a consumer's positively valanced brandrelated cognitive, emotional and behavioral activity during or related to focal consumer/brand interactions" (Hollebeek et al., 2014). Researchers advocate that role of customer engagement with the brand in online service recovery needs to be explored which will help in understanding the customer-brand relationship (Islam et al., 2019). Specifically, more research is needed in the direction of the consequences of the recovery when firm assumes the responsibility of recovery solution (firm recovery), when customers co-create the recovery solution (joint recovery), when customers assume the sole responsibility of recovery solution (customer recovery), specifically in terms of customer's engagement with the service provider (So et al., 2020). It is important to uncover the relationship between customer participation in service recovery and customer-brand engagement (CBE hereafter) as it facilitates designing better recovery mechanisms (Islam et al., 2019). Additionally, it is also required to validate the impact of customer participation in recovery when customers recover from the service failure since customer-firm interaction fosters customer-brand relationships. Thus, the study wishes to contribute to the existing literature by understanding the relationship between customer participation in service recovery and CBE and e-WoM. Mobile apps are the interfaces with the least employee interference and the interaction facilitated during customer participation in service recovery helps in bridging the service gap (Sugathan et al., 2017). Thus, it is important to understand the impact of customer participation in service recovery in the context of mobile apps to confirm whether customer collaboration yields favorable outcomes.

\section{Theoretical Framework Development}

Service recovery is an effective tool to alleviate customers' negative behaviors followed by a service failure. Theory of co-creation and resource-based theory suggests that two parties involved in the value creation process have mutual benefits associated with the outcome 
(Heidenreich et al., 2014; Ranjan \& Read., 2016). Firms and customers can co-create a service recovery to improve the service experience and recovery evaluations (Roggeveen et al., 2011; Dong et al., 2016; Suganathan et al., 2017). Recovery evaluations are better with the co-creation of recovery (joint recovery) as it facilitates better integration of firm resources and customer resources in the form of effort, information, and time (Xu et al., 2014). Customer participation in service recovery has emerged as a research domain due to the emerging role of customers in different types of services (Suganathan et al., 2017; Bagherzadeh et al., 2020). Prior studies provide evidence that customer participation in service recovery (Dong et al., 2008, Roggeveen et al., 2011) facilitates better service recovery while using self-service technology platforms such as mobile apps (Zhu et al., 2013). Drawing inputs from the theory of co-creation and resource-based theory, three variants of service recovery, firm recovery, joint recovery, and customer recovery were proposed by the past researchers (Fang et al., 2008; Dong et al., 2008; Park \& Ha, 2016; Xu et al., 2014; Dong et al., 2016).

Past studies have examined the impact of customer participation in the service recovery process and found that customer contribution to the recovery has a significant impact on the recovery outcomes. It was found that co-created service recovery (joint recovery) generally leads to better customer service recovery evaluations in terms of recovery satisfaction and repurchase satisfaction (Dong et al., 2008; Roggeveen et al., 2011; Xu et al., 2014). Ever since the emergence of co-created service recovery, most of the studies have tried to investigate antecedents and consequences of customer participation in the recovery process (Dong et al., 2008; Xu et al., 2012; Zhu et al., 2013; Dong et al., 2016). Further, few studies have examined the customer journey from customer participation in service delivery to service recovery (Heidenreich et al., 2015; Suganathan et al., 2017; Bagherzadeh et al., 2020). These studies provide pragmatic evidence that customer collaboration in the service recovery process improves the recovery evaluations. It was found that joint recovery significantly mitigates the effect of service failures and improves customer satisfaction than the other two (firm, customer) recovery types. However, there is scant research connecting the domain of service recovery with $\mathrm{CBE}$ especially when customers collaborate with the service firm to co-create the recovery solution (Islam et al., 2019). Customer participation service recovery may influence customer engagement as it facilitates resource integration in the form of information sharing, giving efforts in the recovery process. Customer's involvement in the recovery might influence the customer-brand relationship. Pragmatic evidence suggests that customer involvement is a potential antecedent of CBE (France et al., 2016). Thus, the study studies the relationship between service recovery and CBE to fill the void of research in studying the nexus between service recovery and customer-brand relationship in the interactive service platforms. The above discussion highlights the importance of investigating the impact of three recovery types will give more meaningful insights for the service recovery in the interactive app service platforms. Further, the study also investigates the impact of customer-brand engagement on e-WoM as it is one of the effective ways to exhibit customer-brand engagement (Tu et al., 2018).

Three recovery types were used in this study as recommended by Dong et al. (2016). Recovery types are classified into three (firm recovery, joint recovery, and customer recovery) based on the customers' level of participation in the recovery. Firm recovery refers to the situation where a firm itself does the recovery with no/less amount of effort from the customer. Joint recovery refers to the situation where the customer and service provider both contribute to the 
recovery. Customer recovery refers to the situation where a customer himself finds out a way to recover from the failure without any help from the service provider.

\subsection{Service Recovery and Recovery Satisfaction}

The theory of co-creation proposes that customers create value by sharing information, investing their resources, and customizing the service outcomes (Fang et al., 2008). This theory can be extended to the domains of service recovery in the form of mandatory or nonmandatory customer participation depending on the service context (Dong et al., 2016). When a service failure occurs, customers contribute to the recovery by providing the required information in a remote service setting such as a mobile application (Roggeveen et al., 2011). Customers participating in service recovery attach credit to their contribution and report better satisfaction with the outcome (Dong et al., 2008). The theory of co-creation coupled with resource-based theory suggests that resource collaboration enriches the co-creation experience as there is an adequate fit of mutual interests of both the parties involved. Das and Teng (2000), in their 'Resource-Based theory' also state that the two parties involved in a collaborative work realize greater value with combined synergies. There is less scope for customer-firm interaction to integrate their resources in firm recovery and customer recovery as firms may not have access to the failure-related information. Thus, it is difficult for a firm to identify an ideal solution for failure as there is less scope for paying heed to customers' expectation of the recovery solution (Heidenreich et al., 2014; Dong et al., 2016). Joint recovery offers more scope to accommodate the customer recovery expectations (Dong et al., 2016), thus leading to greater recovery satisfaction. Drawing inputs from the above theories it can be inferred that joint recovery has a positive influence on recovery satisfaction when customers collaborate with the service provider using their resources, as they can exercise more control and exert influence on the solution to the service failure. Thus, the below hypothesis can be stated:

H1a: In case of service recovery, customer recovery results in greater recovery satisfaction than firm recovery.

H1b: In case of service recovery, joint recovery results in greater satisfaction than customer recovery.

H1c: (Combining H1a and H1b) In case of service recovery, joint recovery results in greater satisfaction than firm recovery and customer recovery.

\subsection{Service Recovery and CBE}

Previous studies on customer-brand relationship have considered CBE as a psychological state that occurs by customer interactions with the brand (France et al., 2016; Mohanty \& Dey, 2020). Extant research suggests that customer participation and consumer interactions with the service provider offer mutual benefits to both the customer and service provider (Bagozzi \& Dholakia, 2006). It is also suggested that such interactions will make the consumer more enthusiastic about the brand, thereby resulting in positive engagement with the service provider/brand (Vivek et al., 2012). Customer participation in service recovery offers scope for the interactions that might lead to increased engagement with the brand (Hazee et al., 2017). Service recovery can be a relational driver of CBE or antecedent an antecedent to behaviors reflecting CBE (Liu et al., 2021; So et al., 2020).

Social exchange theory posits that customers are better engaged with a brand when brand resources are integrated with customers' resources during the customer journey with the 
service firm (Guo et al., 2017). A customer's collaboration to the recovery process involves integration of customers' resources (time, effort, knowledge) with firm resources (technology, employees, guidelines) which leads to greater CBE. Thus, drawing inputs from social exchange theory and studies in the domain of customer engagement and service recovery, the following hypotheses are framed.

H2a: In case of service recovery, Customer recovery results in greater CBE than firm recovery.

H2b: In case of service recovery, Joint recovery results in greater CBE than customer recovery.

H2c: (Combining $\mathrm{H} 2 \mathrm{a}$ and $\mathrm{H} 2 \mathrm{~b}$ ) In case of service recovery, joint recovery results in greater CBE than firm recovery and customer recovery.

\subsection{Service Recovery and e-Word of Mouth (e-WoM)}

In the era of digitization, the electronic form of word of mouth (e-WoM) has overtaken the traditional form of word of mouth (Srivastava \& Sivaramakrishnan, 2020), and customers are no longer believe the product/service-related information provided by the brand. Instead, they trust the consumer-generated review information posted on various websites/apps (Al-Htibat \& Garanti, 2019). The term e-WoM is defined as the extent to which an individual says positive things about the brand to others on the internet (Srinivasan et al., 2002). Extant literature has widely studied the concept of e-WoM in the services marketing domain as customers use it as a key factor to arrive at purchase decisions (Haywood, 1989). There is a greater possibility that customers engage in negative word of mouth when they face service failure. The theory of cocreation posits that customers evaluate their efforts more positively which results in positive post-consumption behaviors such as word of mouth and switching intention (Zhu et al., 2013). Furthermore, e-WoM has been used increasingly in service recovery-related studies due to its importance associated with customers' post-purchase behavior (Xie et al., 2019).

Service recovery studies have examined the impact of different types of service recovery satisfaction (Choi \& Choi 2014; Jung \& Seock, 2017) and found that service recovery strategies improve the positive word of mouth and mitigate negative word of mouth. Additionally, research studies found that co-creation of service recovery enhances service performance and improves behavioral intentions of the customers as they actively contribute to the service (Xie et al., 2019). Co-creation of recovery implies that firm resources and customer resources are used to arrive at the desired resolution for the customers which improves the post-purchase behaviors of the customers after a service failure. Although customer recovery facilitates greater control, the onus lies on the customer to make efforts to overcome the service problem. Thus, customer recovery may not result in better post-purchase behavior than joint recovery. Thus, the following hypotheses are framed:

H3a: In case of service recovery, Customer recovery results in greater e-WoM than firm recovery.

H3b: In case of service recovery, Joint recovery results in greater e-WoM than customer recovery.

H3c: (Combining H3a and H3b) In case of service recovery, joint recovery results in greater eWoM than firm recovery and customer recovery. 


\subsection{CBE and e-Word of Mouth}

e-WoM forms the consumer attitude toward a brand and influences the expectations of customers from a brand in the interactive platforms (Loureiro et al., 2017). This is also an act of meeting and sharing opinions on the internet, which provides usability, accessibility of information that was unavailable in traditional offline WoM (Seo et al., 2020, p.3). Customer participation in service creation and information sharing will lead to increased positive wordof-mouth intentions among the customers (Dessart et al., 2015), with the improved engagement with the brand during meaningful interactions in online platforms (Srivastava \& Sharma, 2017). Studies on customer engagement have emphasized the creation of CBE, which occurs by interactive customer experiences with the brand and in turn influences the consumer attitude and behaviors (Mollen \& Wilson, 2010; Dessart et al., 2015).

Recent studies on CBE have explored the role of CBE in enhancing word-of-mouth intention (Mohanty \& Dey, 2020; Acharya, 2020). It has been argued that customer's affective engagement drives emotional attachment with the brand, and it has a higher probability of resulting in positive word-of-mouth in online platforms (Jung \& Seock, 2017). It was found that customers with high emotional attachment with the brand display high level of WoM than those of less engaged customers (Hudson et al., 2015). Thus, the following hypothesis can be framed to examine the impact of CBE on e-WoM:

H4: CBE has a positive impact on e-WoM.

\subsection{CBE, Recovery Satisfaction and e-WoM}

Extant literature has studied customer satisfaction as a consequence of CBE. Past research studies generally suggest that customer satisfaction consists of an overall evaluation of the consumer-brand interactions following purchase or consumption of a product or a service (Hollebeek et al., 2014). Before the development of CBE literature in marketing, the term employee engagement received considerable attention from the organization behavior (OB) researchers (Robinson et al., 2004; Saks, 2006). Empirical investigation indicated a positive relationship between employee engagement and employee job satisfaction (Saks, 2006). Analogously, the nature of such a relationship may also extend to the marketing domain for understanding the relationship between CBE and customer satisfaction (Hollebeek, 2011). It is argued that customer emotional attachment with the brand has positive impacts on e-WoM and the brand relationship quality constructs such as trust, commitment \& satisfaction (Hollebeek, 2011; Hudson et al., 2015). Empirical investigations have also found a significant positive impact of customer engagement on the relationship quality (consists of; trust and customer satisfaction) (So et al., 2014). In addition, researchers have also suggested that customer engagement with the brand enhances customer satisfaction and therefore, customer satisfaction could be a potential consequence of CBE (Hollebeek, 2011). Empirical findings suggest a positive impact of CBE on customer satisfaction (Srivastava \& Sivaramakrishnan, 2020). On the other hand, study on customer satisfaction have acknowledged the importance of customer satisfaction for enhancing the word-of-mouth intention of customers (Kim et al., 2009). An array of empirical research in the domain of marketing has found a positive relationship between customer satisfaction and WoM (Sivadas \& Jindal, 2017).

The same relationship may be expected between CBE and recovery satisfaction since cognitive and affective responses are increasingly viewed as essential in researching how customers evaluate service recovery (Schoefer, 2008, Ozkan-Tektas \& Basgoze, 2017). Further, research 
on service recovery found that cognitive and affective response of customer plays an important role in the formation of recovery satisfaction (Schoefer, 2008). Further, the empirical investigations indicated a significant effect of customer positive emotion on recovery satisfaction (Schoefer, 2008; Xu et al., 2019). Research has also found the indirect effect of customer's cognitive and affective responses on recovery satisfaction in the service failure context (Varela-Neira et al., 2008). It can be argued that the recovery process facilitates cognitive and affective engagement in the form of positive emotion which acts as a judgment factor for recovery satisfaction and post-recovery behavior of the customer. Based on the above arguments, the following hypothesis can be stated:

H5: Recovery satisfaction mediates the relationship between CBE and e-WoM.

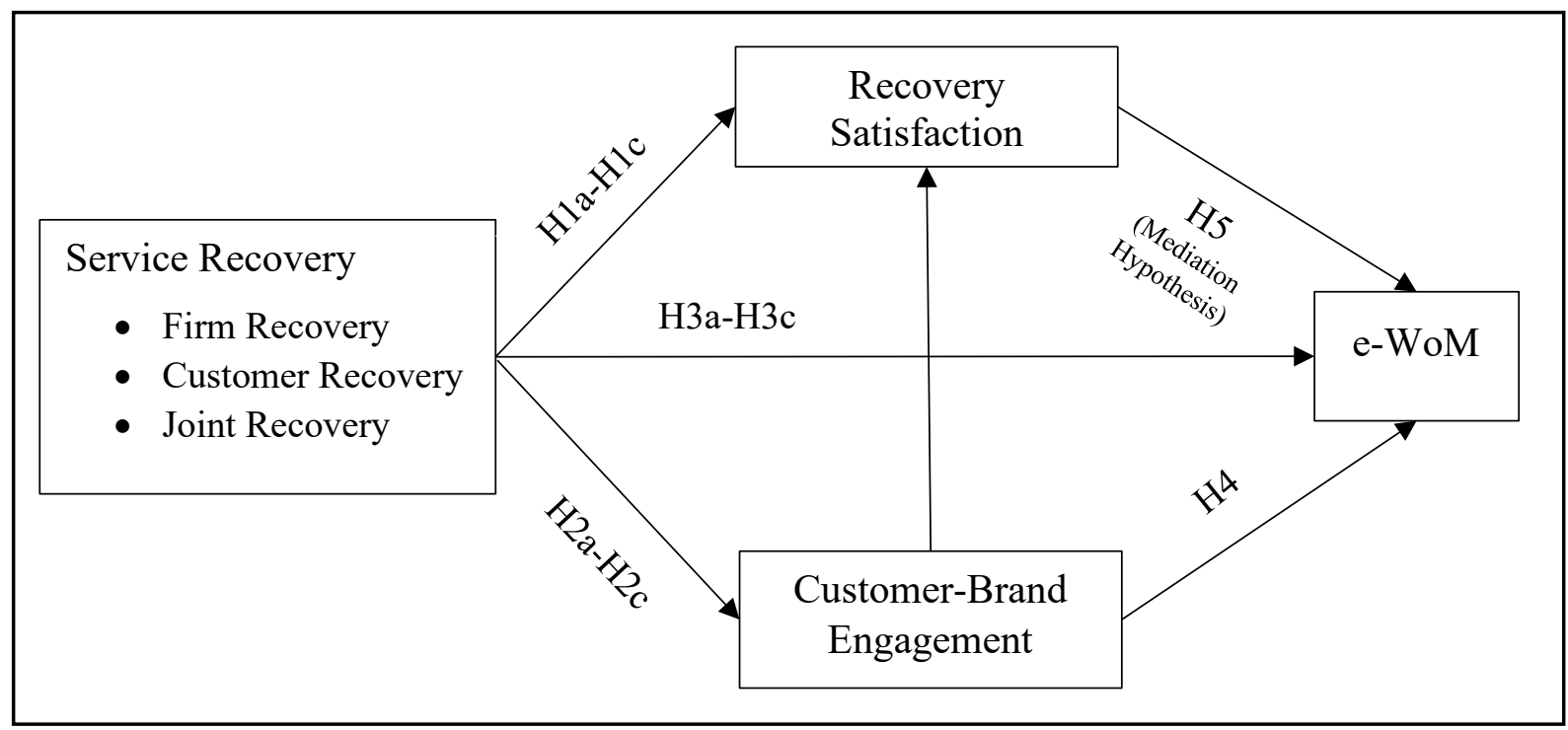

Figure 1. Conceptual Framework

\section{Methodology}

\subsection{Sampling and Data Collection Procedure}

Data were gathered online from the consumers of food delivery applications (apps) in India (e.g., Zomato \& Swiggy). The context was chosen based on three major reasons. These are a) fastest growing industry with a compounded average growth rate (CAGR) of 11 percent (Research \& Markets, 2020); b) lower customer retention rate compared with other app-based service categories (Statista, 2019); and c) provide an interactive platform for better service creation (Lim et al., 2015).

The study used a between-subjects experimental design for the primary data collection. Three different scenarios were designed featuring the service recovery (customer, firm, and joint) conditions in the app-based food delivery services (refer to Appendix for scenarios). All the three scenarios were manipulated by varying the level of customer participation in the recovery process consistent with Dong et al. (2008); and Dong et al. (2016). Firm recovery scenario had limited participation from the customer to the recovery process. Joint recovery condition had contribution from both the customer and firm to the recovery process. Customer recovery condition had the major contribution and efforts from the customer to the recovery process. A sample size of 495 food delivery app users in the millennial category participated during the online experiments. The sample size of 495 was based on the three major criteria. 
These are a) for maintaining equal no-of sample size across three groups of experimental conditions (firm recovery, customer recovery, and joint recovery) in MANOVA; b) In order to meet the criteria of multivariate normality assumptions, the study followed the guideline provided by Koenker \& Bassett (1978). According to Koenker \& Bassett (1978) regression estimates follow an asymptotic multivariate normal distribution in case of large sample sizes; c) study has also suggested that a researcher would have better power to detect small effect size in regression analysis with approximately 30 respondents per variable (Voorhis \& Morgan, 2007). Additionally, it was also found that the empirical power of all the test statistics reaches $100 \%$ when the sample size is as large as 500 (Tong \& Bentler, 2013). Millennials were recruited for the study as past studies suggest that millennial customers are more empowered with the usage of electronic devices and involved in the interaction with the apps and service provider (Vivek et al., 2012). Additionally, the study has also found that millennials are three times more likely to order food online than their parents (Cheng, 2018). A screening question asked to check whether the respondent has ordered food online and has experienced at least one service failure in the last six months. Qualified respondents were then randomly assigned to any one of the three scenarios of the study. Three independent variables were manipulated based on customer collaboration with the service recovery. The study also included one question on scenario realism to understand if the scenarios replicate real time true scenarios faced by customers. Respondents were asked to evaluate the recovery after reading the scenario and provide ratings for recovery satisfaction, CBE, and e-WoM.

\subsubsection{Sample Characteristics}

The demographic profile of the 495 sample respondents reflected their representation of the target population. The sample had $57 \%$ of male and $43 \%$ of female respondents. A majority (55.4\%) of the respondents held a post-graduate degree. Nearly $36 \%$ of the respondents had a family income of Indian National Rupee 500,000-1,000,000 followed by more than 1,000,0001,500,000 (24\%).

\subsection{Measures}

All the constructs were measured using a five-point Likert scale of 1 to 5 , where 1 indicates 'strongly disagree' and 5 indicates 'strongly agree' except the manipulation check for recovery scenarios. These scenarios were measured using a summative score of both customer and firm contribution to the recovery. The summative scale was required to measure the relative contribution of the customers with respect to the firm in the service recovery process. Manipulation of three service recovery types was checked using a single item scale by Dong et al. (2016). The scale item: 'Using a 10-point scale, please rate both your and firm contribution to the described recovery solution (both should add up to 10)'. Recovery satisfaction was measured using a three items scale by Dong et al. (2016). A sample item includes: 'How satisfied were you about the solution to this problem?'. CBE was measured using a 10 items scale of Hollebeek et al. (2014). A sample item includes: 'using my food app gets me to think about that brand'. Similarly, e-WoM was measured using a four items scale adopted from Srinivasan et al. (2002). A sample item of the e-WoM scale includes: 'I would like to introduce the food app brand to others.

\subsection{Data Analysis}

The data gathered was analyzed mainly in two phases. The first phase consisted of preliminary analysis comprising the test of internal consistency, bivariate Pearson correlation coefficient, 
mean, standard deviation (SD), skewness, and kurtosis. The possible impact of common method bias $(\mathrm{CMB})$ was also checked using Harman's single factor test for all the latent constructs. The second phase of the data analysis consisted of hypotheses testing. Multivariate analysis of variance (MANOVA) was used to examine the differential impact of three service recovery types on recovery satisfaction $\mathrm{H} 1_{(\mathrm{a}-\mathrm{c})}, \mathrm{CBE}\left(\mathrm{H} 2_{(\mathrm{a}-\mathrm{c})}\right.$, and e-WoM $\left(\mathrm{H} 3_{(\mathrm{a}-\mathrm{c})}\right.$. Following Hayes (2017) procedure of examining the mediating effect, regression analysis was performed using PROCESS macro, model-4 to examine the mediating role of recovery satisfaction between CBE and e-WoM relationship (H4-H5).

\subsubsection{Common Method Bias}

To avoid and detect the possible impact of common method variance bias (CMB) in survey data, the study used both ex-ante measures and ex-post techniques suggested by Podsakoff et al. (2003). Several ex-ante strategies were adopted by the study to prevent the CMB effect. These are (1) items of the latent constructs were jumbled up and were not labelled, (2) respondents were informed about the anonymity and confidentiality of their responses during the data collection. However, to test the possible existence of CMB in the data, Harman's single factor test was performed by constraining all the variables into a single factor with rotation constraint. The results revealed that the total variance explained by a common factor solution accounted for 39.37\%, which is less than the cut-off limit (50\%) (Podsakoff et al., 2003; Malhotra et al., 2006). The study also checked the full collinearity test as a comprehensive procedure for the identification of CMB (Koch \& Lynn, 2012). The results indicated that all VIF values of the construct were below the 3.3 threshold mark (Kock, 2015), indicating no CMB problem. Finally, the study also followed the correlation matrix approach (Presented in Table 1) suggested by Pavlou et al. (2007) to detect CMB. The result does not indicate any highly correlated factors $(r>.90)$ in the analysis. Therefore, the result suggested the absence of CMB in the data.

\subsubsection{Preliminary Analysis}

The findings of this study provide insights into the relationships among the constructs under investigation. In the first phase of data analysis, the internal consistency of the constructs was tested. Cronbach's alpha values for all the latent constructs; recovery satisfaction, CBE, and electronic-word-of-mouth were found to be $0.91,0.88$, and 0.78 respectively (Refer Table 1). Since all the constructs had a Cronbach's alpha value of more than 0.70, internal consistency was achieved (Nunnally, 1978; Hair et al., 2010). The data collected from the sample also meets the normality assumptions criteria as the skewness and kurtosis value lie between the range of \pm 2 and \pm 7 respectively, suggested by Trochim \& Donnelly (2008).

\begin{tabular}{|l|l|l|l|l|l|l|l|l|l|l|}
\hline & & Min & Max & Mean & SD & Skewness & Kurtosis & 1 & 2 & 3 \\
\hline 1 & RS & 1.0 & 5.0 & 3.35 & 0.9 & -0.26 & -0.23 & $\mathbf{0 . 9 1}$ & & \\
\hline 2 & CBE & 1.7 & 5.0 & 3.67 & 0.6 & -0.92 & 1.43 & $.51^{* *}$ & $\mathbf{0 . 8 8}$ & \\
\hline 3 & e-WoM & 1.0 & 5.0 & 3.82 & 0.7 & -0.95 & 1.54 & $.44^{* *}$ & $.68^{* *}$ & $\mathbf{0 . 7 8}$ \\
\hline
\end{tabular}

Table 1. Descriptive statistics, correlation coefficients, and Cronbach's alpha $(N=495)$

**** $\mathrm{p}<.01$.

Note: Values along the diagonal in boldface represent Cronbach's alpha coefficients; RS = recovery satisfaction; $\mathrm{CBE}=$ consumer-brand engagement; $\mathrm{e}-\mathrm{WoM}=$ electronic-word of mouth . 


\subsubsection{Scenario Realism and Manipulation Check}

Realism check was performed to know whether the scenarios replicate true recovery scenarios faced by customers in real-time. The results indicated that the mean score of all the recovery scenarios (Mean Joint $=4.13$, and Mean Firm $=4.35$, and Mean Customer $=4.11$ ) represent realistic scenarios. Manipulation check of three levels of customer contribution in recovery scenarios was done using ANOVA. The results revealed a significant difference among the levels of customer contribution to the recovery scenarios across three recovery scenarios ( $\mathrm{F}$ 822.93, $\mathrm{p}<.001)$. The mean score of customer contribution in customer recovery scenario (Mean Customer $=8.08$ ) is higher than the mean scores of joint recovery and firm recovery scenarios (Mean Joint $=4.89$; and Mean Firm $=2.55$ ).

\section{Results}

Once psychometric properties of the constructs were found to be valid, and manipulations were found to be successful the study proceeded for hypothesis testing. MANOVA and regression analysis using PROCESS macro were performed to test the hypothesized relationships.

MANOVA results indicated that the main effect of service recovery on recovery satisfaction, $\mathrm{CBE}$, and e-WoM were significant. The mean scores of all the dependent variables are presented in Table 2. The homogeneity of variance test for all the mean scores of the dependent variables was found to be insignificant indicating the robustness of the model.

\begin{tabular}{|l|l|l|l|l|l|}
\hline Recovery Type & N & $\begin{array}{l}\text { Recovery Satisfaction } \\
\text { (RS) Mean }\end{array}$ & $\begin{array}{l}\text { CBE } \\
\text { Mean }\end{array}$ & $\begin{array}{l}\text { e-WoM } \\
\text { Mean }\end{array}$ & Robustness test \\
\hline Firm Recovery & 165 & 3.02 & 3.42 & 3.59 & $\begin{array}{l}\text { Wilk's Lambda }=0.89 \\
\text { F = 9.98*** }\end{array}$ \\
\hline Joint Recovery & 165 & 3.67 & 3.91 & 4.05 & \\
\hline Customer Recovery & 165 & 3.34 & 3.67 & 3.80 & \\
\hline
\end{tabular}

Table 2. Main Effects of Service Recovery on Recovery Satisfaction, CBE \& e-WoM ${ }^{* * *} p<.01$.

\begin{tabular}{|l|l|l|l|l|}
\hline \multicolumn{2}{|l|}{ Dependent Variable } & Mean Difference & Std. Error \\
\hline \multirow{2}{*}{$\begin{array}{l}\text { Recovery } \\
\text { Satisfaction }\end{array}$} & \multirow{2}{*}{ Joint Recovery } & Firm Recovery & $.6419^{* * *}$ & 0.09874 \\
\cline { 3 - 5 } & \multirow{2}{*}{ CBE } & Customer Recovery & $.3280^{* *}$ & 0.09874 \\
\hline \multirow{2}{*}{ e-WoM } & \multirow{2}{*}{ Joint Recovery } & Firm Recovery & $.4927^{* * *}$ & 0.07247 \\
\cline { 3 - 5 } & Joint Recovery & Customer Recovery & $.2473^{* *}$ & 0.07247 \\
\cline { 3 - 5 } & & Customer Recovery & $.2415^{* *}$ & 0.08006 \\
\hline
\end{tabular}

Table 3. Multiple Comparison of Means

${ }^{* *} p<.01 .{ }^{* * *} p<.001$.

The main effect of service recovery on recovery satisfaction was found to be significant $(\mathrm{F}=$ 21.13, $\mathrm{p}<.05)$. The study also tested for the homogeneity of variance using Levene Statistic. The result indicated that the homogeneity of variance test was found to be insignificant 
(Levene Statistic: 0.311). The mean score presented in Table 2 indicated that the mean score of joint recovery in recovery satisfaction $\left(R S_{J R}=3.67\right)$ is greater than customer recovery $\left(R S_{C R}=\right.$ $3.34)$ and firm recovery $\left(\mathrm{RS}_{\mathrm{FR}}=3.02\right)$. The multiple comparisons of means result presented in Table 3 found significant differences among the group means values, supporting H1a, H1b, and $\mathrm{H} 1 \mathrm{c}$.

The main effect of service recovery on CBE was found to be significant $(F=23.11, p<.05)$, and the test of homogeneity for variances was found to insignificant suggesting variance within the mean scores (Levene Statistic $=.293$ ). Further, the results of multiple comparisons of means analysis provided support for the hypotheses pertaining to the relationship between three recovery types and $\mathrm{CBE}$. Joint recovery resulted in more customer engagement with the brand $\left(\mathrm{CBE}_{\mathrm{JR}}=3.91\right)$ than firm recovery $(\mathrm{CBEFR}=3.42)$ or customer recovery $(\mathrm{CBECR}=3.67)$, supporting $\mathrm{H} 2 \mathrm{a}, \mathrm{H} 2 \mathrm{~b}$, and $\mathrm{H} 2 \mathrm{c}$.

The main effect of service recovery on e-WoM was found to be significant $(F=16.794, p<.05)$ suggesting the differential impact of the three recovery types on e-WoM. Levene Statistic (.476) indicated a non-significant homogeneity in the mean scores of e-WoM. The results indicated that joint recovery results in greater e-WoM intention $\left(\mathrm{e}-\mathrm{WoM}_{\mathrm{JR}}=4.05\right)$ than firm recovery $(\mathrm{e}-$ $\left.W_{O M}=3.59\right)$ and customer recovery $\left(e-W_{0 M}=3.80\right)$, in support of H3a, H3b, and H3c.

The present study tested the mediation-related hypothesis, H5 (CBE ๑Recovery Satisfaction ๑) e-WoM) by using the procedure suggested by Hayes (2017). The statistical significance of the mediation test was checked by executing the bootstrapping procedure of the SPSS PROCESS macro. The results indicated that both the direct and the indirect effect of CBE on e-WoM $\left(\beta_{\text {indirect }}=0.06\right.$ and $\left.\beta_{\text {direct }}=0.69\right)$ were statistically significant at a $95 \%$ confidence interval, given that the interval contains non-zero elements $(\mathrm{LLCI}=0.02, \mathrm{ULCI}=0.11)$. The above results are in support of the validity of study hypothesis $\mathrm{H} 4$ and $\mathrm{H} 5$. The mediating role of recovery satisfaction was found in the relationship between CBE and e-WoM. Moreover, the standardized value of $\mathrm{CBE}(\beta=0.62)$ is higher than the value of recovery satisfaction $(\beta=0.11)$ indicating a predominant role of $\mathrm{CBE}$ in explaining e-WoM.

\section{Discussion}

This study examined the relationship among the service recovery, recovery satisfaction, CBE, and e-WoM drawing inputs from theory of co-creation, resource-based theory, and social exchange theory. Our study investigated the differential impact of service recovery with varying levels of customer-firm interaction in app-based service recovery. The research questions were: a) Does the type of service recovery impact the recovery satisfaction and CBE differently? b) does the type of service recovery influence the e-WoM differently? c) does recovery satisfaction mediate the relationship between CBE and e-WoM?

In line with the existing literature (Roggeveen et al., 2011; Dong et al., 2016), the present study found joint recovery to have better impact on satisfaction associated with the recovery. Roggeveen et al. (2011) provided empirical evidence that customer collaborating with firm during the recovery process report better recovery outcomes than those who do not collaborate with firm when they face service failure with the airline service providers. The present study results augment this effect suggesting that joint recovery produces better recovery outcomes. Examining service recovery in a technology-based service, Heindenreich et al. (2014) found that joint recovery provides better recovery outcomes. The results from the 
present study strengthen the arguments in favor of joint recovery suggesting that co-creation of recovery helps when customers face a service failure with a food delivery app which is a technology-based service. Additionally, the findings of the study extend the work of Dong et al. (2016) by examining the relationship between joint recovery to customer-brand relationship.

The results also indicate that consumers collaborating with the service provider for the recovery solution exhibit greater $\mathrm{CBE}$ than consumers who receive recovery solutions from the firm or who fix the service failure with their own efforts or minimum support from the firm. The hypotheses results are consistent with the theoretical inputs drawn from resourcebased theory and social exchange theory which suggests that interaction in the joint recovery facilitates information sharing and extending efforts during the service recovery process. Thus, it was empirically tested that joint recovery results in greater CBE than firm recovery and customer recovery. Similarly, the results also indicate that co-creation of recovery improved the e-WoM among the customers after a service failure. It is consistent with extant literature (Jung \& Seock, 2017) which suggests that co-creation of service recovery emanates positive word of mouth. It can be inferred that the customer-firm interactions facilitate a greater control over the service performance leading to positive word of mouth. Furthermore, the results support the mediation role of recovery satisfaction on the relationship between CBE and eWoM. This offers a new perspective to the service recovery literature by examining the role of recovery satisfaction in determining the customer brand relationships.

\subsection{Theoretical Contributions}

The study offers four major theoretical contributions. First, drawing inputs from the theory of co-creation and resource-based theory, the study investigated the relationship between customer participation in service recovery and CBE. This offers a new perspective to both service recovery and customer-brand relationship domains, suggesting that collaborating with customer during service recovery might provide an opportunity to improve CBE. Customers invest their time and share the information and put efforts to recover from the service failure which requires integration of firm's resources at the same time. This proves that resource integration process involved in a joint recovery can be source of motivation for the customers to engage with the service firm.

Second, drawing inputs from social exchange theory, the study investigated the relationship between CBE and e-WoM. Customers realize the benefits associated with joint recovery and exhibit better engagement with service provider which leads to e-WOM responses from the customers. Customers' engagement with the service provider can become a relational driver to emote positive WoM intentions after a successful service recovery. This is consistent with social exchange theory as customers are encouraged by the interactions and are likely to exhibit social behaviors in the form of e-WOM. Customers' engagement with the service provider can become a relational driver to emote positive WoM intentions after a successful service recovery.

Third, the mediating role of recovery satisfaction in the relationship between CBE and e-WoM was found to be significant, suggesting that recovery satisfaction will influence the relationship between, $\mathrm{CBE}$ and e-WoM. Further, the study also contributes the extant literature as it addresses the call to explore the role of CBE in service recovery (Hollebeek, 2018), especially when customers co-create the recovery (Van Vaerenbergh et al., 2018). 
Finally, the study provides extended support for considering service recovery as a journey which can be used as a touch point to build long term relationships with customers (Van Vaerenbergh et al., 2019). Drawing on the above theories, the present study offers meaningful insights into the customer-firm collaboration during service recovery and its differential impact on recovery satisfaction, $\mathrm{CBE}$, and e-WoM.

\subsection{Managerial Implications}

It is difficult for any firm to offer service with zero defects; therefore, firms can use the cocreation of recovery to improve customer-firm interaction during the recovery process. The study offers four managerial implications for the industry practitioners. First, it is advisable for the firms to design service recovery in the mobile apps with better interactivity as customer collaboration with the firm has a wider scope for engagement with the service provider. For instance, firms like Swiggy, Uber, Ola etc. have introduced interactive chatbots to help with any deviations in the service. Second, it is suggested that the service firms invest more in creating awareness about the joint recovery process as it might help the customers to be future ready to handle service failure as major service failures in a mobile app service take place independent of employee interference.

Firms can leverage social media to create awareness of the joint recovery process since the virtual presence facilitates awareness among the observing customers in the social media (Schaefers \& Schamari, 2016) Third, service firms can also promote brand communities that help the customers to share their stories of successful recovery instances to enhance e-WoM. Fourth, service firms should offer rewards for integrating their resources during the recovery process which fosters a better customer brand relationship (Shulga \& Busser., 2020). For example, customers who participate in the joint recovery can be rewarded with a coupon or additional discount which might motivate a customer to maintain long-term relationship with the brand (Hwang et al. 2020). The findings indicate that customer's participation in service recovery plays a key role in determining the customer recovery evaluations. Thus, service firms should emphasize on defining customer's role as a partial employee during the recovery process. The findings of the study provide managers with the opportunity to identify the resources that can be integrated during joint recovery process. The service firm should collect the all the information about the resources that customers are willing to integrate during the recovery process so that the firm identifies appropriate resources to be deployed for improved customer-brand relationship after a service failure.

\section{Limitations and Directions for Future Research}

Like other behavioral studies, this study also has a few limitations. First, the results of the study cannot be generalized across all the service context as the nature of service failures might vary depending on the context (Forbes, 2008).

Second, the study has used single platform interaction happens in a service recovery; However, the service interactions might be complex as the service providers are integrating the services across multi-channels. Thus, studying the multi-channel interactions in the service recovery may offer insightful results.

Third, the impact of service recovery initiation (Xu et al., 2014) on the relationship among service recovery, $\mathrm{CBE}$ and $\mathrm{e}-\mathrm{WoM}$ can be an interesting future research direction as the customer initiation of recovery may reduce or increase the CBE based on the outcome. 
Fourth, future research may also investigate the role of recovery speed on the relationship between service recovery and customer engagement with the brand as the prior studies in service recovery suggest that recovery speed influences the impact of recovery on customer evaluations and customer psychological association with the brand (Roggeveen et al. 2011). Finally, it is also interesting to examine the comparison of the resource exchange-based joint recovery with a goal-based response to the service failure which addresses the goal heterogeneity (Van Vaerenbergh et al., 2019). For example, a customer who faces service failure while looking for utilitarian need fulfillment may respond differently from a customer who faces hedonic need fulfillment (Park \& Ha, 2016).

\section{Conclusion}

This research work is one of the first to investigate the relationships among service recovery, $\mathrm{CBE}$, and e-WoM from the perspective of customer participation in service recovery. This study provides the evidence for the impact of co-creation of recovery on CBE and recovery satisfaction, which in turn will influence the e-WoM intentions of the customers followed by a successful service recovery. Findings of the study also provide support for the mediating effect of recovery satisfaction in the relationship between CBE and e-WoM after a successful service recovery.

\section{References}

Acharya, A. (2020). The impact of brand familiarity, customer brand engagement and selfidentification on word-of-mouth. South Asian Journal of Business Studies, 10(1), 29-48.

Al-Htibat, A., \& Garanti, Z. (2019). Impact of interactive eReferral on tourists' behavioral intentions. Marketing Intelligence \& Planning, 37(5), 527-541.

Bagherzadeh, R., Rawal, M., Wei, S., \& Saavedra Torres, J. (2020). The journey from customer participation in service failure to co-creation in service recovery. Journal of Retailing and Consumer Services, 54, 102058.

Bagozzi, R., \& Dholakia, U. (2006). Antecedents and purchase consequences of customer participation in small group brand communities. International Journal of Research in Marketing, 23(1), 45-61.

Cheng, A. (2018). Millennials Are Ordering More Food Delivery, But Are They Killing The Kitchen, Too?. Forbes, Retrieved October 17, 2019, from https://www.forbes.com/sites/andriacheng/2018/06/26/millennials-are-orderingfood-for-delivery-more-but-are-they-killing-the-kitchen-too/?sh=31974523393e

Cheung, F., \& To, W. (2016). A customer-dominant logic on service recovery and customer satisfaction. Management Decision, 54(10), 2524-2543.

Choi, B., \& Choi, B. (2014). The effects of perceived service recovery justice on customer affection, loyalty, and word-of-mouth. European Journal of Marketing, 48(1/2), 108-131.

Dabholkar, P., \& Spaid, B. (2012). Service failure and recovery in using technology-based selfservice: Effects on user attributions and satisfaction. The Service Industries Journal, 32(9), $1415-1432$. 
Das, T., \& Teng, B. (2000). A Resource-Based Theory of Strategic Alliances. Journal of Management, 26(1), 31-61.

Dessart, L., Veloutsou, C., \& Morgan-Thomas, A. (2015). Consumer engagement in online brand communities: A social media perspective. Journal of Product $\&$ Brand Management, 24(1), 28-42.

Dong, B., Evans, K., \& Zou, S. (2008). The effects of customer participation in co-created service recovery. Journal of The Academy of Marketing Science, 36(1), 123-137.

Dong, B., Sivakumar, K., Evans, K., \& Zou, S. (2016). Recovering coproduced service failures. Journal of Service Research, 19(3), 291-306.

Fang, E., Palmatier, R., \& Evans, K. (2008). Influence of customer participation on creating and sharing of new product value. Journal of The Academy of Marketing Science, 36(3), 322-336.

Forbes, L. (2008). When something goes wrong and no one is around: Non-internet self-service technology failure and recovery. Journal of Services Marketing, 22(4), 316-327.

France, C., Merrilees, B., \& Miller, D. (2016). An integrated model of customer-brand engagement: Drivers and consequences. Journal of Brand Management, 23(2), 119-136.

Guo, L., Gruen, T., \& Tang, C. (2017). Seeing relationships through the lens of psychological contracts: The structure of consumer service relationships. Journal of The Academy of Marketing Science, 45(3), 357-376.

Hair, J. F., Black, W. C., Babin, B. J., \& Anderson, R. E. (2010). Multivariate data analysis (7th ed.). Upper Saddle River, New Jersey: Prentice Hall.

Hayes, A. F. (2017). Introduction to mediation, moderation, and conditional process analysis: A regression-based approach. Guilford publications.

Haywood, K. M. (1989). Managing word of mouth communications. Journal of Services Marketing, 3(2), 55-67.

Hazée, S., Van Vaerenbergh, Y., \& Armirotto, V. (2017). Co-creating service recovery after service failure: The role of brand equity. Journal of Business Research, 74, 101-109.

Heidenreich, S., Wittkowski, K., Handrich, M., \& Falk, T. (2014). The dark side of customer cocreation: Exploring the consequences of failed co-created services. Journal of The Academy of Marketing Science, 43(3), 279-296.

Hollebeek, L. (2011). Demystifying customer brand engagement: Exploring the loyalty nexus. Journal of Marketing Management, 27(7-8), 785-807.

Hollebeek, L. (2018). Individual-level cultural consumer engagement styles: Conceptualization, propositions and implications. International Marketing Review, 35(1), 42-71.

Hollebeek, L., Glynn, M., \& Brodie, R. (2014). Consumer brand engagement in social media: Conceptualization, scale development and validation. Journal of Interactive Marketing, 28(2), 149-165. 
Hsu, L., Wang, K., Chih, W., \& Lin, W. (2019). Modeling revenge and avoidance in the mobile service industry: Moderation role of technology anxiety. The Service Industries Journal, 124 .

Hudson, S., Roth, M., Madden, T., \& Hudson, R. (2015). The effects of social media on emotions, brand relationship quality, and word of mouth: An empirical study of music festival attendees. Tourism Management, 47, 68-76.

Hwang, Y., Gao, L., \& Mattila, A. S. (2020). What recovery options to offer for loyalty reward program members: Dollars vs. Miles?. International Journal of Hospitality Management, 87, 102496.

Islam, J. U., Rahman, Z., \& Hollebeek, L. D. (2019). The role of consumer engagement in recovering online service failures: An application of service-dominant logic. In Handbook of Research on Customer Engagement. Edward Elgar Publishing.

Jung, N., \& Seock, Y. (2017). Effect of service recovery on customers' perceived justice, satisfaction, and word-of-mouth intentions on online shopping websites. Journal of Retailing and Consumer Services, 37, 23-30.

Kim, W., Ng, C., \& Kim, Y. (2009). Influence of institutional DINESERV on customer satisfaction, return intention, and word-of-mouth. International Journal of Hospitality Management, 28(1), 10-17.

Kock, N. (2015). Common method bias in PLS-SEM: A full collinearity assessment approach. International Journal of e-Collaboration (ijec), 11(4), 1-10.

Kock, N., \& Lynn, G. (2012). Lateral collinearity and misleading results in variance-based SEM: An illustration and recommendations. Journal of the Association for information Systems, 13(7).

Koenker, R., \& Bassett, G. (1978). Regression quantiles. Econometrica, 46(1), 33-50. doi: $10.2307 / 1913643$

Kozinets, R., De Valck, K., Wojnicki, A., \& Wilner, S. (2010). Networked narratives: Understanding word-of-mouth marketing in online communities. Journal of Marketing, 74(2), 71-89.

Lim, S., Bentley, P., Kanakam, N., Ishikawa, F., \& Honiden, S. (2015). Investigating country differences in mobile app user behavior and challenges for software engineering. IEEE Transactions on Software Engineering, 41(1), 40-64.

Liu, X., Shin, H., \& Burns, A. (2021). Examining the impact of luxury brand's social media marketing on customer engagement: Using big data analytics and natural language processing. Journal of Business Research, 125, 815-826.

Loureiro, S. M. C., Gorgus, T., \& Kaufmann, H. R. (2017). Antecedents and outcomes of online brand engagement: The role of brand love on enhancing electronic-word-ofmouth. Online Information Review, 41(7), 985-1005. 
Malhotra, N., Kim, S., \& Patil, A. (2006). Common method variance in is research: A comparison of alternative approaches and a reanalysis of past research. Management Science, 52(12), 1865-1883.

Mohanty, P., \& Dey, D. (2020). Consumer-brand engagement with e-commerce market place brands. Journal of Electronic Commerce in Organizations, 18(3), 21-37.

Mollen, A., \& Wilson, H. (2010). Engagement, telepresence and interactivity in online consumer experience: Reconciling scholastic and managerial perspectives. Journal of Business Research, 63(9-10), 919-925.

Nunally, J. C. (1978). Psychometric theory (2nd ed.). New York: McGraw-Hill.

Ozkan-Tektas, O., \& Basgoze, P. (2017). Pre-recovery emotions and satisfaction: A moderated mediation model of service recovery and reputation in the banking sector. European Management Journal, 35(3), 388-395.

Park, J., \& Ha, S. (2016). Co-creation of service recovery: Utilitarian and hedonic value and post-recovery responses. Journal of Retailing and Consumer Services, 28, 310-316.

Pavlou, P. A., Liang, H., \& Xue, Y. (2007). Understanding and mitigating uncertainty in online exchange relationships: A principal-agent perspective. MIS Quarterly, 31(1), 105-136.

Podsakoff, P. M., Mackenzie, S. B., Lee, J., \& Podsakoff, N. P. (2003). Common method biases in behavioral research: A critical review of the literature and recommended remedies. Journal of Applied Psychology, 88(5), 879-903.

Ranjan, K. R., \& Read, S. (2016). Value co-creation: concept and measurement. Journal of the Academy of Marketing Science, 44(3), 290-315.

Research \& Markets (2020). Online food delivery services global market report 2020-30: Covid19 growth and change. Retrieved May 17, 2020, from https://www.

researchandmarkets.com/reports/5024095/online-food-delivery-services-globalmarket?utm_source=dynamic\&utm_medium=BW\&utm_code=jzdnfb\&utm_ campaign=1388109+-+Global+Online+Food+Delivery+Services+Market+(2020+to+ 2030)+-+COVID-19+Growth+and+Change\&utm_exec=jamu273bwd.

Robinson, D., Perryman, S., \& Hayday, S. (2004). The drivers of employee engagement. Brighton: Institute for Employment Studies.

Roggeveen, A. L., Tsiros, M., \& Grewal, D. (2011). Understanding the co-creation effect: When does collaborating with customers provide a lift to service recovery? Journal of the Academy of Marketing Science, 40(6), 771-790.

Saks, A. M. (2006). Antecedents and consequences of employee engagement. Journal of Managerial Psychology, 21 (7), 600-619.

Schaefers, T., \& Schamari, J. (2016). Service recovery via social media: The social influence effects of virtual presence. Journal of Service Research, 19(2), 192-208. 
Schoefer, K. (2008). The role of cognition and affect in the formation of customer satisfaction judgements concerning service recovery encounters. Journal of Consumer Behaviour, 7(3), 210-221

Seo, E. J., Park, J. W., \& Choi, Y. J. (2020). The effect of social media usage characteristics on eWOM, trust, and brand equity: Focusing on users of airline social media. Sustainability, 12(4), 1-18.

Shulga, L. V., \& Busser, J. A. (2020). Hospitality employee and customer role in value cocreation: Personal, organizational and collaborative outcomes. International Journal of Hospitality Management, 91, 102648.

Sivadas, E., \& Jindal, R. P. (2017). Alternative measures of satisfaction and word of mouth. Journal of Services Marketing, 31(2),119-130.

So, K. K., King, C., Sparks, B. A., \& Wang, Y. (2014). The role of customer engagement in building consumer loyalty to tourism brands. Journal of Travel Research, 55(1), 64-78.

So, K. K. F., Li, X., \& Kim, H. (2020). A decade of customer engagement research in hospitality and tourism: A systematic review and research agenda. Journal of Hospitality $\mathcal{E}$ Tourism Research, 44(2), 178-200.

Srinivasan, S. S., Anderson, R., \& Ponnavolu, K. (2002). Customer loyalty in e-commerce: An exploration of its antecedents and consequences. Journal of Retailing, 78(1), 41-50.

Srivastava, D., \& Sharma, R. W. (2017). Developing a model for studying the antecedents and effects of Word of Mouth (WoM) and e-WoM marketing based on literature review. Jindal Journal of Business Research, 6(1), 25-43.

Srivastava, M., \& Sivaramakrishnan, S. (2020). The impact of eWOM on consumer brand engagement. Marketing Intelligence \& Planning, 39(3), 469-484.

Statista (2019). Mobile app downloads worldwide from 2018 to 2024. Retrieved May 15, 2020 from https://www.statista.com/statistics/1010716/apple-app-store-google-play-appdownloads-forecast/

Sugathan, P., Ranjan, K. R., \& Mulky, A. G. (2017). A typical shifts post-failure: Influence of co-creation on attribution and future motivation to co-create. Journal of Interactive Marketing, 38, 64-81.

Tong, X., \& Bentler, P. M. (2013). Evaluation of a New Mean Scaled and Moment Adjusted Test Statistic for SEM. Structural Equation Modeling: A Multidisciplinary Journal, 20(1), 148-156.

Trochim, W. M., \& Donnelly, J. P. (2008). Research methods knowledge base. Mason, OH: Atomic Dog/Cengage Learning.

Tu, Y., Neuhofer, B., \& Viglia, G. (2018). When co-creation pays: Stimulating engagement to increase revenues. International Journal of Contemporary Hospitality Management, 30(4), 2093-2111.

Van Vaerenbergh, Y., Hazée, S., \& Costers, A. (2018). Customer participation in service recovery: a meta-analysis. Marketing Letters, 29(4), 465-483. 
Van Vaerenbergh, Y., Varga, D., De Keyser, A., \& Orsingher, C. (2019). The service recovery journey: Conceptualization, integration, and directions for future research. Journal of Service Research, 22(2), 103-119.

Voorhis, C. R., \& Morgan, B. L. (2007). Understanding Power and Rules of Thumb for Determining Sample Sizes. Tutorials in Quantitative Methods for Psychology, 3(2), 43-50.

Verkijika, S., \& De Wet, L. (2019). Understanding word-of-mouth (WOM) intentions of mobile app users: The role of simplicity and emotions during the first interaction. Telematics and Informatics, 41, 218-228.

Vivek, S. D., Beatty, S. E., \& Morgan, R. M. (2012). Customer Engagement: Exploring Customer Relationships Beyond Purchase. Journal of Marketing Theory and Practice, 20(2), 122-146.

Xie, X. Z., Tsai, N. C., Xu, S. Q., \& Zhang, B. Y. (2019). Does customer co-creation value lead to electronic word-of-mouth? An empirical study on the short-video platform industry. The Social Science Journal, 56(3), 401-416.

Xu, Y., Tronvoll, B., \& Edvardsson, B. (2014). Recovering service failure through resource integration. The Service Industries Journal, 34(16), 1253-1271.

Xu, X., Liu, W., \& Gursoy, D. (2019). The impacts of service failure and recovery efforts on airline customers' emotions and satisfaction. Journal of Travel Research, 58(6), 1034-1051.

Zhu, Z., Nakata, C., Sivakumar, K., \& Grewal, D. (2013). Fix it or leave it? customer recovery from self-service technology failures. Journal of Retailing, 89(1), 15-29.

\section{Appendix: Service Recovery Scenarios}

\section{Firm Recovery}

You have ordered food from a restaurant nearby through your favourite 'Food' delivery app. Upon receiving the food, you have realized that the delivery boy has delivered incomplete order (few items were missing from the order). When you have checked with the delivery boy you were informed that the refund will be provided for the missing items. You have shared the order number and list of items missing through the chat board provided on the mobile app. You have received the refund for the missing items.

\section{Joint Recovery}

You have ordered food from a restaurant nearby through your favourite 'Food' delivery app. Upon receiving the food, you have realized that the delivery boy has delivered incomplete order (few items were missing from the order). When you have checked with the delivery boy you were informed that the refund will be provided for the missing items. You have shared the order number and list of items missing with the help of support system available on the app. You were provided with a link which had guidelines about how to get refund. The process required you to share the order details and pictures of the items received along with details of missing details. You have followed the instructions provided to initiate the refund process. You have received the refund for the missing items. 
of mobile applications

\section{Firm Recovery}

You have ordered food from a restaurant nearby through your favourite 'Food' delivery app. Upon receiving the food, you have realized that the delivery boy has delivered incomplete order (few items were missing from the order). When you have checked with the delivery boy you were informed that the refund will be provided for the missing items. You have found the helpline number after gathering information form internet and checked for the refund process of food delivery service provider with your efforts. You have received the refund after initiating the refund process.

Copyright: (C) 2021 authors. This is an open-access article distributed under the terms of the Creative Commons Attribution-NonCommercial 3.0 Australia License, which permits noncommercial use, distribution, and reproduction in any medium, provided the original author and AJIS are credited.

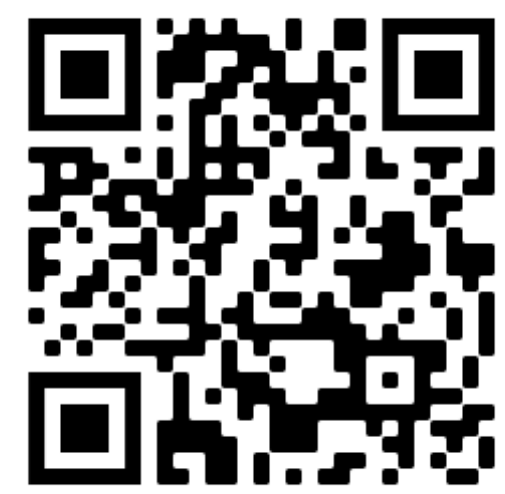

